\title{
Supporting the Creation of Shared Value
}

\author{
Dr John Mendy
}

Lincoln International Business School

University of Lincoln

LN6 7TS

\section{Email: jmendy@lincoln.ac.uk}

\begin{abstract}
The core of Porter and Kramer's Shared Value (SV) proposal (2011) is that companies support individuals and groups of individuals (those they do not employ) so they start building businesses and thereby contribute to the activities of the parent companies. It is argued that the proposal requires a method not only for its implementation, but also one to change the parent companies so they act like those they support. To identify this method the results of a study are presented. It made use of semi-structured interviews concerning how a number of companies dealt with challenges. The results suggest that individuals developed ways to increase their ability to act expertly, i.e. resiliently, in the face of the challenges. The results were used to formulate the method to implement the SV proposal. It is argued that this method is similar to, but also substantially different from the scientific method (used to acquire knowledge rather than gain expertise as the new method is designed to do). The formulation of the method helps to evaluate the SV proposal: it is insufficient to realise its own aims - but also suggests a way to do so.
\end{abstract}

KEYWORDS: shared value, expertise, method, change, resistance 


\section{INTRODUCTION}

In 2011 Porter and Kramer proposed a redefinition of capitalism after criticising it for having led companies to focus on realising their own objectives independent of their social and national environment - thereby creating general socio-economic problems. These include poverty, ethical financial misconduct and lack of health and safety. Such problems have been left for governments to deal with, partly at the expense of business. When this led to large financial claims as well as stricter regulations companies came up with their own strategies to deal with the problems, like Corporate Social Responsibility. The implementation of such strategies remains separate from the companies' main activities, just as happens when governments are dealing with the problems. This suggested a new strategy that Porter and Kramer refer to as 'Shared Value' (SV). They argue that this strategy provides many advantages compared to previous ones and even helps to create a new form of capitalism. The strategy requires companies to provide organisations and individuals outside of the company with the tools to become partners. Activities that originally are separated from the main activities of a company would thus morph into activities that those involved would benefit from as well as the company itself. This would reduce the burden on governments as well as introduce other benefits such as helping to avoid negative externalities.

The core element of the proposal appears to be that existing companies are to export their way of working and have anyone benefit who otherwise might become the victim of that way of working and in need of government care. That way of working is severely criticised however as the source of seriously negative externalities: companies' 'narrow' strategies generate socio-economic problems, resist societal regulation and lack a social purpose. What is to be exported is quite different therefore. The aim is that companies and individuals acquire a social purpose, are expected to change their use of resources and to be innovative and apparently open to the future. The authors of the proposal appear to claim that what is intended for export will also change the original companies as they will begin to understand the advantages of a more open type strategy - but at the same time fear that they will 'resist even well-constructed regulation' when challenged to implement that change (ibid, p. 14).

The proposal is less practical than one would expect therefore. It is restricted to suggesting an objective - albeit an attractive one - that should replace the popular objectives of “commoditization”, price competition, little true innovation, slow organic growth and not 
clear competitive advantage’ (ibid, p. 6), or more generally "profit maximisation” (ibid, p. 16). The proposal thus raises a question, which is taken as the research question of this paper: 'what method might help to realise the proposed objective?' The question obviously is not new and has received a number of answers in the management literature, which Porter and Kramer do not discuss or compare (Lewin, 1947; Kotter, 2008).

One reason for this omission may be that the proposed objective is special in some sense and hence that the question requires a new answer. The results of a study of employees' efforts when their companies have to respond to life-threatening challenges suggest such an answer (Mendy, 2012). This study questioned the way some employees are able to resist managerial directives that continue to adopt the 'narrow' strategy that Porter and Kramer criticise. A methodology of individual interviewing was used. The method that employees use appears to give body to these authors' proposal. Its aim is to help individuals increase their ability to formulate new objectives and recognise potential resources to realise them. Gaining this ability is labelled gaining expertise. It allows individuals to anticipate and reduce the negative externalities as well as increase the positive impact and effects of their actions on what happens in their companies.

\section{LITERATURE REVIEW}

The proposal (SV) has received global attention and its components have been extensively discussed - both theoretically as well as practically by well-known multinational companies (Moon et al., 2011). While many of the discussions focussed on clarifying the meaning of SV, Moon and colleagues corroborated Porter and Kramer's proposal whilst adding “core competence” as a strategic value redefining component (p. 49). Others explored contextual information such as the role of value-sharing "agents", a topic related to the present paper (Bouckenooghe, 2010, p. 503). Restructuring according to the SV model proved to take time and to be easily derailed, for example due to a lack of access to finance and due to management incompetence (Teittinen et al., 2013; Doern, 2009; Ford et al., 2008).

In line with the initial analysis presented above implementation appears to imply a change in culture (Bock et al., 2012; Orlikowsky, 2007). This has led to suggestions for methods that focus on ways to create and use resources (Tassabehji \& Isherwood, 2014). These methods have been criticised as well as they have not specified how Porter and Kramer's proposal can 
actually be implemented. (Garezzi \& Terzi, 2005; Lenseges et al., 2016). Although Crane et al. (2014) highlight SV's "shortcomings" (p. 130) by critiquing the functionalist, economic view of the firm and questioning its value-creation credentials, they did not reflect on whether there might be a method of implementing their proposal.

\section{ANALYSIS}

The principle of SV apparently is that companies help create the environments to enable members of groups other than themselves to reshape their individual activities and thereby contribute both to these groups and to the originating or parent companies - apparently under the assumption that the parent companies will thereby abandon their evil ways of maximising profits and forgetting their negative effects on others. From this perspective in the case of farmers one should focus "on improving growing techniques and strengthening the local cluster of supporting suppliers [...] in order to increase farmers' efficiency, yields, product quality and sustainability" (Porter and Kramer, 2011, p. 5). This means taking on a "broad range of roles in meeting the needs of workers, communities, and supporting businesses” (ibid, p. 6). This way SV “opens up many ways to serve new needs, gain efficiency, create differentiation, and expand markets” (ibid, p. 7).

The following examples provide some further insights into the actions that are envisaged. "Intel and IBM are both devising ways to help utilities harness digital intelligence in order to economize on power usage. Wells Fargo has developed a line of products and tools that help customers budget, manage credit, and pay down debt” (ibid, p. 7). "Waterhealth International [...] uses innovative water purification techniques to distribute clean water at minimal cost to more than one million people in rural India, Ghana and the Philippines" (ibid, p. 7). "The British retailer Marks and Spencer's ambitious overhaul of its supply chain, for example, which involves steps as simple as stopping the purchase of supplies from one hemisphere to another, is expected to save the retailer $£ 175$ million annually by fiscal 2016, while hugely reducing carbon emissions” (ibid, p. 9). “[...] Hindustan Unilever is creating a new direct-tohome distribution system, run by underprivileged female entrepreneurs, in Indian villages of fewer than 2000 people (ibid, p. 10). More generally: “a living wage, safety, wellness, training, and opportunities for the advancement for employees have [positive effects] on productivity” (ibid, p. 11). 
These examples suggest that, while each focuses on collectives (i.e. companies or groups of individuals), all interventions have to be implemented by individuals. This does indeed imply a revolutionary change. If the aims of SV are achieved, capitalism is no longer about exploiting individual workers, but about helping them to improve their lives. Unfortunately, standard research methodology (i.e. the 'scientific method') is not designed or even intended to help. Its aim is to facilitate the acquisition of knowledge, i.e. of a resource that anybody can use to realise any objective. It does not support gaining expertise. The concept of expertise refers to individuals who a) are able to choose an objective in some place and time (or a finite number of them), b) can identify resources that are accessible in that place and time, c) are able to use a scheme that allows the actor to recognise mistakes in the realisation of the objectives as well as correct them. That is to say, applying the scientific method helps in providing knowledge, but not in recognising accidental resources or in developing schemes. This implies that any individual actor retains quite a few freedoms if the only method to help improve his or her actions is the scientific method. What is needed is something entirely different therefore: a method to activate the collection of objectives and resources and help strive for high quality links between them. To ensure that errors can be identified and corrected this method should be like the scientific method, i.e. help initiate experiments in which objectives and resources are anticipated and their links compared.

Given that applying the scientific method only leads to knowledge and hence not to any support in identifying objectives, resources and schemes, one has to look elsewhere for ideas to help gain expertise. As one source for such a method the following study came to mind (Mendy, 2012). The data were collected via two surveys of managers and employees of four UK-based SMEs that faced special challenges in 2004/2005. Their CEOs described their plight as having to fight for survival. A total of eighty-five interviews were held between 2004/2005 and 2011 (68 in the first, 17 in the second set). The first survey questioned what strategies were developed to deal with the challenges (including that of firing staff) and how people reacted to the implementation of these strategies. The second survey questioned later developments, including all four having survived. Table 1 summarises the contextual data.

The four SMES faced the following challenges. Longhurst was under intense government pressure to improve the volume and quality of its housing facilities and to evaluate staff performance. Lagat was challenged to increase their educational provision whilst staff numbers and funding were being cut. The Care Quality Commission challenged Eden 
Supported Housing to provide affordable, quality care: its owners had started to maximise profits and performance just like Bakkavor. Laurens-Patisserie had to work hard at integrating different ethnicities, as local supermarkets were demanding nutrition labelling on cake products. Bakkavor bought the organisation and emphasised on financial returns.

Table 1: Companies, interview role categories and number of respondents

\begin{tabular}{|c|c|c|}
\hline Companies & Role categories & Total number of respondents \\
\hline $\begin{array}{l}\text { Bakkavor-Laurens } \\
\text { Patisserie }\end{array}$ & $\begin{array}{l}\text { Employees } \\
\text { Managers }\end{array}$ & $\begin{array}{l}10 \text { employees, } 7 \text { managers }=17 \text { in } \\
2004 / 05 \\
2 \text { employees, } 3 \text { managers }=5 \text { in } 2011\end{array}$ \\
\hline Longhurst Housing & $\begin{array}{l}\text { Employees } \\
\text { Managers }\end{array}$ & $\begin{array}{l}10 \text { employees, } 7 \text { managers }=17 \text { in } \\
2004 / 05 \\
2 \text { employees, } 2 \text { managers }=4 \text { in } 2011\end{array}$ \\
\hline Lagat & $\begin{array}{l}\text { Employees } \\
\text { Managers }\end{array}$ & $\begin{array}{l}10 \text { employees, } 7 \text { managers }=17 \text { in } \\
2004 / 05 \\
2 \text { employees, } 2 \text { managers }=4 \text { in } 2011\end{array}$ \\
\hline Eden Housing & $\begin{array}{l}\text { Employees } \\
\text { Managers }\end{array}$ & $\begin{array}{l}10 \text { employees, } 7 \text { managers }=17 \text { in } \\
2004 / 05 \\
2 \text { employees, } 2 \text { managers }=4 \text { in } 2011\end{array}$ \\
\hline
\end{tabular}

Respondents waived anonymity. Interviews lasted an hour and each participant was asked to describe developments in their company. Three researchers independently reviewed, interpreted, axially-coded and thematised the data into themes/categories, following Alvesson and Skoldberg (2000). The results have been summarised in Table 2. Two types can be identified. One is a series of steps that describes how each company responded to the challenges. The other is a series of descriptions of themes that refer to the assumed objectives of each step.

The responses of the interviewees identify what objectives managers attempted to implement using what resources. The objectives tended to go into the direction of a reduction of the variety of individual contributions and to focus on realising a reduced set of objectives, in particular short-term maximising of profits. Employees tended to resist the reduction in two ways. One was by presenting counter arguments, the other by going underground, i.e. by 
concealing their objections and trying to implement them without the support of the managers - and even in opposition to them.

The responses could also be organised in terms of six stages in a process. In Table 2 an interpretation of the stages is added, in terms of four themes: 1) establishing new structures and practices, 2) enhancing ways of communicating, 3) fostering strategic collaborations and 4) establishing clusters of resistance. The last category (number 4) is of special importance. It refers to employees starting to develop ways of their own to contribute to the survival of their companies. They appear to develop objectives that are independent of their company's objectives and to become able to recognise resources that may help realise them in their interaction with others. In short, the employees' activities can be interpreted as experimenting with the aim of gaining expertise - rather than of acquiring knowledge.

What is remarkable is the development of employees' initiatives. They apparently begin to realise that the managers are trying to implement precisely those strategies that make their companies unable to deal with the new challenges: less space for individual initiatives, less willing to recognise outside resources such as using other companies as resources as part of cooperation, claiming more power over employees, etc. The employees start to experiment with what they would do (objectives) and how these may be realised through resources that they can create through interaction. This means they begin to be able to choose alternatives that make their companies able to deal with the challenges and hence become more resilient.

Table 2. Summary of Study's Results \& 4 interpretive themes

\begin{tabular}{|l|l|l|}
\hline Data's 6 stages & Characteristics & 4 themes \\
\hline 1 & $\begin{array}{l}\text { Managers realise the need for } \\
\text { change and introduce require- } \\
\text { ments to limit initiatives and } \\
\text { focus on supporting the } \\
\text { realisation of one objective. }\end{array}$ & $\begin{array}{l}\text { Establishing new streamlining } \\
\text { structures and practices }\end{array}$ \\
\hline 2 & $\begin{array}{l}\text { Managers introduce punitive, } \\
\text { disciplinary measures. }\end{array}$ & $\begin{array}{l}\text { Establishing new streamlining } \\
\text { structures and practices }\end{array}$ \\
\hline 3 & $\begin{array}{l}\text { Managers start 'harder' } \\
\text { measures to monitor } \\
\text { employees' actions. }\end{array}$ & $\begin{array}{l}\text { Establishing new streamlining } \\
\text { structures and practices }\end{array}$ \\
\hline
\end{tabular}




\begin{tabular}{|l|l|l|}
\hline 4 & $\begin{array}{l}\text { Employees start to cooperate } \\
\text { with colleagues in other } \\
\text { departments. Managers } \\
\text { introduce more checks. }\end{array}$ & $\begin{array}{l}\text { Enhancing recognition what } \\
\text { others can do for you and you } \\
\text { for them }\end{array}$ \\
\hline 5 & $\begin{array}{l}\text { Employees form sub-cultures } \\
\text { and begin to identify tasks } \\
\text { independent of managers. }\end{array}$ & $\begin{array}{l}\text { Establishing groups of people } \\
\text { who gain expertise individually } \\
\text { and collectively }\end{array}$ \\
\hline 6 & $\begin{array}{l}\text { Employees start to increase } \\
\text { collective expertise. Their } \\
\text { companies start to behave as } \\
\text { advised via SV. }\end{array}$ & Fostering strategic expertise \\
\hline
\end{tabular}

The results of the study do not constitute a theory, as the data set cannot be closed: new resources and new objectives may be found at whatever stage of development a company is in. The results describe changes in the way employees behave, but again not as a closed description or theory, but as a process that moves forward due to what the employees want and the changes they want. This makes the study relevant to the analysis of Porter and Kramer's (2011) proposal and to the research question.

This proposal requires that companies are able to export a way of adding value to others without these companies themselves necessarily being able to do that in their own right. This combination seems illogical, which leads to the conclusion that the proposal must be modified. What needs to be added is a method of helping others (individuals and companies) to interact with the initiating or parent company such that all concerned gain expertise (rather than only knowledge by applying the scientific method). It would seem that for such a method to help implement the SV proposal, it must be analogous to the method identified in the study described above (Mendy, 2012). This way its form may be identified - e.g. as consisting of 6 steps or one with a different number of steps as long as it is equivalent to the method that was found in the study.

But it also has to be shown that the new method is operationally viable. This demonstration may proceed by comparing the method with other methods (see Table 3). There appear to be many of them (Kotter, 2008; Lenseges et al., 2016; Kjaerbeck, 2017). Two such methods appear suitable for the present discussion. One is Lewin's (1947) method of “unfreezing” role definitions (Doern, 2009). It has been argued to help employees form new structures, collaborations and communication mechanisms which might help with SV's implementation 
(see Tassabehji \& Isherwood, 2014). Such a comparison should help identify what the method of gaining expertise seems to add and what Lewin's approach appears to be missing. What is missing can be identified as the process of increasing quality, i.e. the comparison of links between possible objectives and resources. This type of testing is not part of Lewin's approach and hence does constitute an answer to the question what it misses: it does not prevent sticking to an old structure when one tries to change to a new organisational structure or culture. A second method might be one that can be derived from Porter and Kramer's proposal. They do not appear to realise the need for such a method, but it is possible to deduce one from the authors' text (also see Crane et al. 2014). It is intended to help realise social purposes by recognising resources and opportunities for the original parent companies. What is missing is again a process of quality control. The examples appear to refer to a hit or miss phenomenon. Anything goes as long as the parent companies make a profit. This suggests that the method of gaining expertise is to be preferred over the two methods discussed here: it includes a process of quality control whereas the others do not.

Table 3. Comparison of Lewin's and Kotter's \& Role of Resistance

\begin{tabular}{|l|l|l|l|}
\hline Steps & Lewin's 3 Stages & Porter and Kramer's SV & Gaining expertise \\
\hline $\mathbf{1}$ & $\begin{array}{l}\text { Unfreeze - remove } \\
\text { constraints that maintain } \\
\text { current situation }\end{array}$ & $\begin{array}{l}\text { Recognise the existence of } \\
\text { human resources that } \\
\text { remain untapped }\end{array}$ & $\begin{array}{l}\text { Identify the activity in which } \\
\text { expertise is to be gained }\end{array}$ \\
\hline $\mathbf{2}$ & $\begin{array}{l}\text { Change - experiment by } \\
\text { allowing individuals to } \\
\text { introduce new values and } \\
\text { recognise new resources }\end{array}$ & $\begin{array}{l}\text { Support and include } \\
\text { efforts to develop new } \\
\text { skills and organisational } \\
\text { structures }\end{array}$ & $\begin{array}{l}\text { Identify links between } \\
\text { personal objectives and } \\
\text { resources and compare them } \\
\text { to establish which has the } \\
\text { highest quality, i.e. is most } \\
\text { effective in increasing } \\
\text { expertise. }\end{array}$ \\
\hline $\mathbf{3}$ & & $\begin{array}{l}\text { Identify strong leaders to } \\
\text { realise vision and manage } \\
\text { more efficiently }\end{array}$ & $\begin{array}{l}\text { Compare links between the } \\
\text { objectives and the resources } \\
\text { to identify links with higher } \\
\text { quality, i.e. are most effective } \\
\text { in increasing expertise. }\end{array}$ \\
\hline $\mathbf{4}$ & $\begin{array}{l}\text { Refreeze } \text { - stabilise the } \\
\text { changes by making } \\
\text { individual initiatives } \\
\text { permanent }\end{array}$ & $\begin{array}{l}\text { Initiate procedures that } \\
\text { help to identify new } \\
\text { resources and new } \\
\text { production processes }\end{array}$ & $\begin{array}{l}\text { Repeat the steps - either as an } \\
\text { individual or as part of a } \\
\text { collective }\end{array}$ \\
\hline
\end{tabular}




\section{DISCUSSION}

It has been argued in the above that the method of gaining expertise is operationally viable, helps to achieve what is required to implement the SV proposal and includes something that other methods appear to be missing: a process of internal checking, i.e. the process of comparing links between objectives and resources. It even appears to be equivalent to the scientific method in terms of its main properties. Many authors have pointed out the need for such a method (Garezzi \& Terzi, 2005; Bouckenooghe, 2010). As can be gleaned from Table 3 , there are four steps, the fourth of which is to start again with step 1.

The initial step is to identify the activity that some individual would like to gain expertise in. One may think of Porter and Kramer's (2011) claim that “Wells Fargo has developed a line of products and tools that help customers budget, manage credit, and pay down debt” (ibid, p. 7). Two types of activity are involved. One is that customers are expected to gain expertise in budgeting, managing credit and the like. The other is that the company Wells Fargo is expected to gain expertise in creating the tools that customers need.

One may continue by exploring for each individual involved what he or she would like to contribute, i.e. one or more objectives he or she would like to realise. These may be linked to resources, such as advice from friends, exploring book-keeping habits, getting a piggy bank or moneybox or getting lists of funding institutions, etc.

A third step would be to compare links between objectives and resources and thereby facilitate choosing the link that has the highest quality. Two types of experiment can be expected. In the first, one tries to find the link that can be deemed to have the highest probability of realising the objective - given one's own experience or that of others. In the second, one implements available links and selects the one that is deemed to have realised the highest quality (at the moment of testing).

The fourth step is to repeat all four steps as a way to add links of high quality to the initial act/activity and thereby increase the expertise someone would need to perform that act. This step appears to be a natural one in most situations. One experiments while acting.

The outcome of taking the steps of the method of gaining expertise may consist of an advice, an instruction or method. It constitutes a scheme one can use to recognise and correct the implementation of the initial act/activity. Further testing may help to generalise instructions (so implementation depends less and less on who is acting, when and where). 
One other argument in favour of the method to gain expertise is that it shares important properties with the method to acquire knowledge - as per the Introduction to the present paper. Both methods include starting by collecting something - either a set of observations or a set of links between personal objectives and resources to implement them. Both methods include mapping the collection onto something else - either a proposition or theory or a link that has the highest quality of the elements of the collection. Both methods are designed to improve the quality of the mapping - either by comparing mappings or by comparing links. The possibility to increase quality by checking against the elements of the collection makes the method superior to methods that do not include this possibility or attempts to realise what SV proposes - like Lewin’s (1947) or Kotter’s (2008) or Bouckenooghe’s (2010).

One further advantage is that the method to gain expertise addresses individuals or groups of individuals. These have to make the comparison possible as is required by the process of increasing quality. Applying the method is not limited to this kind of addressee however. It may also address members of companies and thereby contribute to increases in collective expertise. Examples include team sports - where one depends on the contributions of others. It would appear that Porter and Kramer's (2011) examples actually focus on this form of gaining expertise - next to focussing on developing technical resources to create competent individuals (see Crane et al., 2014) as a way of dealing with SV's implementation “shortcomings” (p. 130).

\section{CONCLUSION}

The stimulus to the present study was Porter and Kramer's (2011) proposal to deal with some of the negative externalities that are due to companies limiting themselves to objectives like "maximisation of profits" and “commoditization". These negative externalities include societal problems such as poverty, job losses and loss of societal infrastructure. Choosing to deal with them triggered the idea that business itself might help as part of its regular operations and not as an added task.

A more detailed analysis of the proposal revealed that its implementation requires that companies change themselves to the type of organisational structure that is advised will help realise the aim of the proposal. It appears to require a method that the parent companies are 
expected to implement when they help others and hence that they will wish to introduce in their own companies. It supports individuals or groups of individuals gaining expertise.

A method for doing so has been described and analysed. It was compared to other methods, in particular that of Lewin (1947) and one that could be derived from Porter and Kramer's proposal (2011) and Crane et al's (2014) later addition. It was derived from a study showing how individual employees sometimes wish to help deal with life-threatening challenges. It helps to activate persons to contribute to the activities of parent companies. It was argued that this method is close to the scientific method in terms of its focus on testing, but differs from it in terms of personal input and subjective objectives and experiences, elements needed to implement SV.

\section{References}

Alvesson, M. \& Skoldberg, K. (2000). Reflexive methodology: New vistas for qualitative research. London: Sage.

Bock, A. J., Opsahl, T., George, G. \& Gann, D. M. (2012). The effects of culture and structure on strategic flexibility during business model innovation. Journal of Management Studies, 49(2), 279-305.

Boukenooghe, D. (2010). Positioning Change Recipients’ Attitudes toward Change in the Organizational Change Literature. The Journal of Applied Behavioural Science, 46(4), 500-531.

Crane, A., Palazzo, G., Spence, L. J. \& Matten, D. (2014). Contesting the value of 'Creating Shared Value’. California Management Review, 56(2), 130-153.

Day, D. \& Kjaerbeck, S. (2013). Positioning in the conversation analytic approach. Narrative Inquiry, 23(1), 16-39.

Doern, R. (2009). Investigating Barriers to SME Growth and Development in Transition Environments: A Critique and Suggestions for Developing the Methodology. International Small Business Journal: Researching Entrepreneurship, 27(3), 275-305.

Ford, J. D., Ford, L. W. \& D’Amelio, A. (2008). Resistance to change: the rest of the story. Academy of Management, 3(2), 362-377. 
Garezzi, M., Terzi, S., Bertazzi, N. \& Brianza, M. (2005). Organisational change and knowledge management in product lifecycle model implementation. International Journal of Product Lifecycle Model, 1(1), 43-51.

Kjaerbeck, S. (2017). Positioning and change in a hospital ward. Journal of Organizational Change Management, 30(1), 43-53.

Kotter, J. P. (2008). A sense of urgency. Harvard: Harvard Business Review.

Lenseges, M. L., Hollensbe, E. C. \& Masterson, S. S. (2016). The human side of restructures: The role of shifting identification. Journal of Management Inquiry, 25(4), 382-396.

Lewin, K. (1947). Frontiers of group dynamics: Concept, method and reality in social science, social equilibria and social change. Human Relations, 1, 5-41.

Mendy, J. (2012). Employees witnessed presence in changing organisations. AI \& Society, Special Issue: Culture and Communication, 27(1), 149 - 156.

Moon, H. C., Parc, J., Yim, S. H. \& Park, N. (2011). An extension of Porter and Kramer's 'Creating Shared Value (SV): Reorienting strategies and seeking international cooperation. Journal of International and Area Studies, 18(2), 49-64.

Orlikowski, W. (2007). 'Sociomaterial practices: exploring technology at work', Organization Studies, 8(9), 1435-1448.

Porter, M. E. \& Kramer, M. R. (2011). The big idea: Creating value rethinking capitalism. Harvard Business Review, January-February Issue.

Tassabehji, R. \& Isherwoood, A. (2014). Management use of strategic tools for innovating during turbulent times. Strategic Change, 23, 63-80.

Teittinen, H., Pellinen, J. \& Jarvenpaa, M. (2013). ERP in action: Challenges and benefits for management control in SME context. International Journal of Accounting Information System, 14(4), 278-296. 